\title{
Increased physical activity, physician recommendation, and senior center participation
}

\author{
James H. Swan ${ }^{1^{*}}$, Keith Turner ${ }^{1}$, Shilpa Shashidhara ${ }^{2}$, David Sanders ${ }^{3}$ \\ ${ }^{1}$ Programs in Applied Gerontology, University of North Texas, Denton, USA; \\ ${ }^{*}$ Corresponding Author: swan@unt.edu; keith.turner@unt.edu \\ ${ }^{2}$ Clinical Ethics Center, Memorial Health System, Springfield, USA; \\ sshashidhara@siumed.edu \\ ${ }^{3}$ Department of Psychology, Sociology, and Social Work, Angelo State University, San Angelo, USA; dsanders5@angelo.edu
}

Received 2 October 2013; revised 8 November 2013; accepted 25 November 2013

Copyright (C) 2013 James H. Swan et al. This is an open access article distributed under the Creative Commons Attribution License, which permits unrestricted use, distribution, and reproduction in any medium, provided the original work is properly cited.

\begin{abstract}
Physical activity is a recognized preventive health measure for seniors and an important focus for senior centers. This paper employs the Andersen Behavioral Model to explore increased physical activity and participation in three types of senior center activities: physical fitness, dancelaerobic classes, and chair exercises. Data were collected in 2006 on 798 and in 2007 on 742 participants at 21 multipurpose senior centers in a large urban county. Logistic regression analysis (PROC RLOGIST in SAS-callable SUDAAN) was employed to predict increased physical activity, with modes of center participation in physical activity as mediating factors. Predisposing and enabling factors predicted both engaging in center-based exercise programs and increases in physical activity; but the strongest predictors of increases in physical activity were needed factors: physician recommendations to increase exercise and to lose weight. Implications are that both SCs and healthcare providers are important to promote physical activity in the older population.
\end{abstract}

Keywords: Physical Activity; Senior Centers; Physician Recommendations; Patient Compliance; Andersen Behavioral Model

\section{INTRODUCTION}

Physical activity is a recognized preventive health measure for elders [1]. Regular activity offers an opportunity to extend years of active independent living [2]. Promotion of physical activity is a major concern for elders [3], hence is an important focus for senior centers (SCs). This paper explores physical activity at SCs in a metropolitan county, employing the Andersen Behavioral Model as a theoretical underpinning.

\section{LITERATURE REVIEW}

Older adults are at risk of sedentary lifestyles $[4,5]$ with inadequate physical activity [6]. Benefits of physiccal activity, including lower risk of mortality [7],accrue into old age, declining only at advanced age [8]. Benefits flow from low levels of activity $[9,10]$, particularly from "moderate" activity for one-half hour per day [11]. Even exercising 15 minutes a day can significantly lower mortality and increase life expectancy [12]. Moderate activeity contributes to self-efficacy and satisfaction with physical functioning [13] and is the most-effective intervention to prevent falls [14]. Moderate activity includes walking $[15,16]$. Vigorous activity may be associated, however, with longer periods of uninterrupted sedentary behavior, which may suggest the need for physical-activity strategies to break up sedentary periods [5]. Physical activity contributes directly to successful aging [17] and quality of life [18]. The Centers for Disease Control and Prevention recommend a blending of moderate, vigorous, and strengthening activities [19].

Physical activity tends to decline with age [20-23]; particularly in the very old, where it is associated with decline in function [24]. Aside from this trend, there appearsa tendency for each older cohort to be more likely to engage in physical activity [25], and in particular an increase may occur upon retirement [26]. The decline is more pronounced with vigorous activity than with moderate physical activity [21].

Senior centers (SCs) are important to the well-being of older Americans [27,28]. SCs need to find ways to best 
promote attendee benefits and vary considerably in their ability to foster behavioral change [29,30]. Although SCs serve all people aged 60 years or over, SC participants are older, more likely to be rural, to have more social contacts, experience better mental health, and have fewer dependencies in activity of daily living [31]. More frequent usersof SC programs tend to be more socially involved [32], more socially active, and non-isolated although many live alone $[33,34]$. In fact, SCs are particularly important as sources of socialization for older women who live alone [27]. Given the importance of social interaction in promoting physical activity [35], social interaction at SCs is critical.

The range of SC programs and activities is extensive, with core elements of: exercise, crafts, meals, information and assistance, opportunities to socialize, and transportation [36]. Choice to participate in physical activity can be seen in the context of presentation with an array of services, with varying physical-activity content. This can include SC participation in walking interventions [37]. Rohr and Lang [38] state: "individuals are choosing and seeking positive social experience, improving the fit of their social environment, and they counterbalance the risks of social contact."

Just as there are many barriers to physical activity in later life [39-41], there are varied models for encourageing physical activity at SCs [42] and elsewhere [3,40, 43-47]. Efforts by senior centers to promote physical activity meet with mixed success [48], prompting concern over successful methods. In particular, factors such as elder expectations of health and quality of life influence their likelihood of engaging in physical activity [2], as are cultural competence, social support, and family involvement [49]. Marcus and associates [50] note, further, that methods best suited for fostering initiation of physical activity are not necessarily those best fit to enhance its maintenance.

Various means of counseling and prescribing physical activity by health care professionals are effective [51-55] Sorensen et al., 2007). Written prescriptions for physical activity have shown efficacy, especially when specifying form and level of activity [56], although the "evidence base" has been described as "thin" [57]. Nevertheless, collaboration between senior centers and primary care has shown success [58]. The issue is whether or not physicians and other health care professionals engage patients regarding physical activity, diet, and issues of overweight, although there is evidence that greater obesity, more chronic conditions, and more contact with providers increases the likelihood especially of the addressing of physical activity by such providers [59].

Women tend to be less involved in physical activity than men $[22,25,60]$. Approximately 47 percent of White women age 75 or greater, 37 percent of older White men, 59 percent of older Black men and 61 percent of older Black women do not engage in regular exercise $[61,62]$.

Racial/ethnic minorities tend to be less involved, in part because of socio-cultural barriers. Interventions should be attuned to specific cultural issues, particularly social interaction and support [25,49,63].

The Andersen Behavioral Model was developed to explain the use of healthcare services in terms of predisposing, enabling, and need factors [64-69]. It has been applied to other types of behavior, however [70], particularly involving organizational features as enabling factors $[25,71,72]$.

\section{METHODS}

Data were collected throughcross-sectional surveys in 2006 on 798 and in 2007 on 742 participants in a large urban county, via staff-administered interviews of program participants at 21 multipurpose senior centers supported by the Area Agency on Aging and a United Way partner agency, as part of an annual program evaluation. Although the data are "found data," collected for a different purpose, items include measures allowing consideration of a model explaining adoption of physical activity, providing wider insight beyond program evaluation.

The SCs, located throughout the county, are open to all people 60 years of age and older, with no income limits or restrictions, providing meals, as well as offering programs designed to ensure a well-balanced approach to physical and mental wellness. Services are provided on a contribution basis and are intended to combat social isolation and lack of proper nutrition. Since sample selection at each SC is not proportional to center size, weighting is used, based on annual participation in congergate meals programs. This measure is used because it is regularly measured and reported consistently across center and over time.

Measures include reported increased physical activity and participation in three types of activities at senior centers: physical fitness, dance/aerobic classes, and chair exercises. Table 1 reports incidence. A little over half reported increasing physical activity in the previous twelve months. About half reported participating in physical fitness activities, and a like number in chair exercises; about one in three reported participation in dance and/or aerobics at the SC.

Predisposing factors address the tendency to use or undertake care, in this case to attend SC activities or to undertake physical activity. Predisposing factorsemployed were: age, race/ethnicity, gender, marital status, living situation, and feelings about the importance of 
Table 1. Dependent and independent variable frequencies.

\begin{tabular}{|c|c|c|c|}
\hline & Weighted Percentage Yes & Unweighted Percentage Yes & $\mathrm{N}$ \\
\hline \multicolumn{4}{|l|}{ Dependent Variables: } \\
\hline Increased Physical Activity in Past Year & 58.2 & 57.3 & 1394 \\
\hline Participates in Physical Fitness at Center & 53.5 & 54.6 & 1203 \\
\hline Participates in Dance/Aerobics at Center & 36.0 & 37.2 & 1117 \\
\hline Participates in Chair Exercises at Center & 53.2 & 55.5 & 1169 \\
\hline \multicolumn{4}{|l|}{ Independent Variables: } \\
\hline \multicolumn{4}{|l|}{ Predisposing } \\
\hline African American ${ }^{\mathrm{a}}$ & 16.7 & 22.2 & 1534 \\
\hline Hispanic $^{\mathrm{a}}$ & 10.5 & 12.8 & 1534 \\
\hline Other Nonwhite ${ }^{a}$ & 4.2 & 3.3 & 1534 \\
\hline Aged 85 or Over & 16.1 & 14.5 & 1482 \\
\hline Male & 30.5 & 30.0 & 1531 \\
\hline Single $^{b}$ & 8.5 & 9.5 & 1534 \\
\hline Widowed $^{\mathrm{b}}$ & 47.1 & 46.7 & 1534 \\
\hline Divorced $^{\mathrm{b}}$ & 12.8 & 12.2 & 1534 \\
\hline Live Alone & 48.7 & 48.1 & 1517 \\
\hline At Least Agree Interactions Important & 92.0 & 92.0 & 1504 \\
\hline Strongly Agree Interactions Important & 35.3 & 34.4 & 1504 \\
\hline \multicolumn{4}{|l|}{ Enabling } \\
\hline Needs Transit Help to Attend SeniorCenter & 12.2 & 11.5 & 1474 \\
\hline Attended Center for at Least 1 Year & 77.2 & 77.9 & 1519 \\
\hline Attended Center for at Least 5 Years & 38.3 & 39.4 & 1519 \\
\hline Attended Center at Least $3 \mathrm{x}$ per Week & 72.1 & 72.6 & 1520 \\
\hline Ctr. Only Interaction Source - Disagree & 56.6 & 55.6 & 1487 \\
\hline Ctr. Only Interaction Source - Agree & 31.7 & 32.7 & 1487 \\
\hline \multicolumn{4}{|l|}{ Need } \\
\hline Physician Said to Increase Exercise & 50.8 & 50.6 & 1411 \\
\hline Physician Said to Control/Lose Weight & 46.4 & 46.8 & 1381 \\
\hline \multicolumn{4}{|l|}{ Continuous Predisposing Variable: } \\
\hline & $\begin{array}{c}\text { Weighted } \\
\text { Mean/(Std. Dev.) }\end{array}$ & $\begin{array}{c}\text { Unweighted } \\
\text { Mean/(Std. Dev.) }\end{array}$ & $\begin{array}{l}\text { Number } \\
\text { of Cases }\end{array}$ \\
\hline Age & $75.1(9.30)$ & $74.9(9.08)$ & 1482 \\
\hline
\end{tabular}

SOURCE: Tarrant county senior center survey.

social interactions. Physical activity may decline with age but may be more-prevalent in older cohorts, controlling for age [25]; further, propensity to participate at SCs may have complex relationships with age. Males may be more predisposed to physical activity. Nonwhites tend to have lower engagement in physical activity. Attitudes toward social interactions at SCs are here considered predisposing because of the importance of such interacttions to SC participation and because peer interaction may influence behaviors such as physical activity.

Enabling factors are concerned with the ability to engage in activities once predisposed to do so. No data were available on income or health coverage. Transportation items were not measured consistently over time, but allowed creating of a measure of whether the respondent needed transportation help in attendance. Other enabling factors included measures directly related to the centers: length and frequency of attendance, and seeing the SC as the major source of social interaction. Although data were not available on geographical or other access to SCs, reports of length of and frequency of attendance were used to represent such enabling factors.

Although physical activity is needed by everyone, levels of need differ. In this study, need is measured byan item on whether "a physician or healthcare professional" instructed respondents to undertake lifestyle changes: to increase exercise or to control or lose weight. Although it would be desirable to have data on recommendations by 
other healthcare professionals, the available study asked only about physician recommendations. Analysis (not reported in tables) showed no significant change across years in physician recommendations to exercise and to control or lose weight. African American and Hispanic were more likely than were white respondents to report both types of recommendations. Reports of both types of physician recommendation decline with age. Males were less likely than females to report recommendations to increase exercise (see Table 1.)

Logistic regression analysis (PROC RLOGIST in SAS-callable SUDAAN) was employed to predict increased physical activity, with modes of center participation in physical activity as mediating factors. SUDAAN was used to adjust standard errors for the weighting scheme. First, the center-based activities were predicted by the independent factors. At the next stage, increase in physical activity was predicted by those independent variables in two equations, both including and excluding the three types of center-based physical-activity.

\section{FINDINGS}

Analysis proceeded in two stages. First, reports of participation in three types of activities at senior centers were separately regressed on the predisposing, enabling, and need factors. Then reports of increase in physical activity were regressed on these factors, both with and without control for participation in senior centers physical activities.

\subsection{Predicting Senior Center Physical Activity}

When center-based activities were regressed on the explanatory measures (Table 2), participants reported greater participation in 2007 than in 2006 in physical fitness and dance/aerobic classes. Predisposing factors in particular were found to be important.

Of special interest are the variations in different SC physical activities by elders of differing racial/ethnic groups. Compared to Whites, African Americans show greater participation in dance/aerobics and chair exercises, Hispanics lower involvement in physical fitness but greater involvement in dance/aerobic classes. These results for participation in SC activities are interesting in light of general tendencies of African American and Hispanic elders to be less involved in physical activity than are non-Hispanic white elders [25].

Males showed lower participation in all three types of $\mathrm{SC}$ activities, interesting in light of a greater tendency of males to undertake physical activity generally. Rather than reflecting male aversion to SC activity programs; this may reflect center success in reducing disparities by drawing more women into such activities. Participation in chair exercise increased with age, likely because such exercises are more-amenable to participation by older center attendees.

Only one enabling factor predicted SC physical activities: those attending at least three times per week had higher participation in all three types of SC activities. That transportation did not appear as a predictor may be attributable to the fact that all of the SCs provide transportation.

Of the need factors, physician recommendations predicted greater likelihood of participation in SC physical fitness. Physician instructions to lose weight predicted greater participation in chair exercises. Respondents were not asked how their physicians recommended physical activity, nor weight-loss strategies. It is thus likely that general recommendations elicited a variety of type of patient responses, whether at SCs or elsewhere.

\subsection{Predicting Overall Increase in Physical Activity}

Table 3 reports analyses predicting reported increase in physical activity, both including and excluding the center-based physical-activity measures. Controlling for the predisposing, enabling, and need factors, such reports were not significantly higher in 2007 than in 2006.

Predisposing factors predicting increased physical activity are Hispanic ethnicity and living alone, each showing lower likelihood. African Americanand other nonwhite respondents do not differ from White respondents on such activity. In light of the much-higher African American reports of participation in SC activities, this suggests that African American exercise through SCs may counteract a general tendency to less physical activity. Such findings might indicate success of SC programs at reducing some racial/ethnic disparities in physical activity among SC attendees.

When the three types of SC activities are controlled (Equation (2)), all three types of SC exercise offerings predict overall physical activity. Hispanic respondents show no lower likelihood of physical activity, suggesting that such a finding in Equation 1 is due to the muchlower likelihood of participating in SC physical fitness classes among SC attendees. Although unmarried respondents no longer show lower likelihood than married respondents, the odds ratio is basically unchanged, suggesting that the issue is lower power in the analysis. Males are more likely than females to report increased physical activity. In conjunction with lower participation by males in SC activities, this suggests that males tend to increase physical activity outside the SCs, females through SC programs. Similar results were obtained for those living alone: lower engagement in chair exercises but greater increases in physical activity when chair exercises and other SC physical activities are controlled, 
Table 2. Logistic regression analysis: physical activities at the seniorcenter.

\begin{tabular}{|c|c|c|c|c|c|c|c|c|c|}
\hline & \multicolumn{3}{|c|}{$\begin{array}{l}\text { Participates in Physical } \\
\text { Fitness at Ctr. }\end{array}$} & \multicolumn{3}{|c|}{$\begin{array}{c}\text { Participates in } \\
\text { Dance/Aerobics at Ctr }\end{array}$} & \multicolumn{3}{|c|}{$\begin{array}{l}\text { Participates in Chair } \\
\text { Exercises at Center }\end{array}$} \\
\hline & $\begin{array}{l}\text { Odds } \\
\text { Ratio }\end{array}$ & $\begin{array}{l}\text { Lower } \\
\text { Bound }\end{array}$ & $\begin{array}{l}\text { Upper } \\
\text { Bound }\end{array}$ & $\begin{array}{l}\text { Odds } \\
\text { Ratio }\end{array}$ & $\begin{array}{l}\text { Lower } \\
\text { Bound }\end{array}$ & $\begin{array}{l}\text { Upper } \\
\text { Bound }\end{array}$ & Odds Ratio & $\begin{array}{l}\text { Lower } \\
\text { Bound }\end{array}$ & $\begin{array}{l}\text { Upper } \\
\text { Bound }\end{array}$ \\
\hline \multicolumn{10}{|l|}{ Independent Variables: } \\
\hline \multicolumn{10}{|l|}{ Predisposing } \\
\hline African American ${ }^{\mathrm{a}}$ & 1.41 & 0.98 & 2.05 & $\underline{1.70}$ & 1.15 & 2.51 & $\underline{3.01}$ & 1.95 & 4.66 \\
\hline Hispanic $^{\mathrm{a}}$ & $\underline{0.41}$ & 0.25 & 0.66 & $\underline{1.81}$ & 1.16 & 1.83 & 1.14 & 0.69 & 1.71 \\
\hline Other Nonwhite ${ }^{a}$ & 2.00 & 0.75 & 5.04 & 1.38 & 0.61 & 3.16 & 0.72 & 0.36 & 1.89 \\
\hline Age & 1.01 & 0.99 & 1.03 & 0.99 & 0.97 & 1.01 & 1.02 & 1.00 & 1.05 \\
\hline Aged 85 or Over ${ }^{b}$ & 0.64 & 0.38 & 1.09 & 1.18 & 0.68 & 2.04 & 0.74 & 0.42 & 1.29 \\
\hline Male & $\underline{0.63}$ & 0.45 & 0.88 & $\underline{0.63}$ & 0.44 & 0.89 & $\underline{0.30}$ & 0.21 & 0.42 \\
\hline Single $^{c}$ & 0.88 & 0.47 & 1.63 & 0.90 & 0.50 & 1.61 & 1.07 & 0.57 & 1.99 \\
\hline Widowed $^{\mathrm{c}}$ & 1.03 & 0.67 & 1.59 & 0.67 & 0.43 & 1.05 & 1.23 & 0.78 & 1.94 \\
\hline Divorced $^{\mathrm{c}}$ & 0.76 & 0.45 & 1.29 & 0.65 & 0.37 & 1.15 & 0.88 & 0.49 & 1.56 \\
\hline Live Alone & 0.77 & 0.54 & 1.10 & 1.09 & 0.76 & 1.56 & $\underline{0.48}$ & 0.33 & 0.71 \\
\hline Agree Interactions Important & 0.85 & 0.47 & 1.55 & 1.38 & 0.76 & 2.51 & 1.27 & 0.72 & 2.23 \\
\hline \multicolumn{9}{|l|}{ Enabling } & 2.08 \\
\hline Needs Transit Help to Attend & 1.04 & 0.66 & 1.63 & 0.71 & 0.44 & 1.15 & 1.49 & 0.93 & 2.39 \\
\hline AttendedSC for at Least $1 \mathrm{Yr}$ & 1.36 & 0.93 & 1.98 & 1.04 & 0.69 & 1.56 & 1.40 & 0.93 & 2.11 \\
\hline AttendedSC for at Least 5 Yrs & 0.91 & 0.65 & 1.28 & 1.16 & 0.81 & 1.55 & 1.01 & 0.71 & 1.43 \\
\hline AttendedSC $3 x$ per Week & $\underline{2.00}$ & 1.42 & 2.82 & $\underline{1.73}$ & 1.18 & 2.52 & 1.56 & 1.10 & 2.21 \\
\hline Only Interaction Source: Disag & 0.85 & 0.53 & 1.37 & 0.89 & 0.52 & 1.50 & 1.31 & 0.64 & 2.69 \\
\hline Only Interaction Source: Agree & 0.88 & 0.52 & 1.47 & 0.76 & 0.43 & 1.35 & 1.24 & 0.73 & 2.09 \\
\hline \multicolumn{10}{|l|}{ Need } \\
\hline MD Said Increase Exercise & 1.56 & 1.10 & 2.23 & 1.30 & 0.90 & 1.87 & 0.88 & 0.55 & 1.41 \\
\hline MD Said Control/Lose Weight & 1.23 & 0.86 & 1.75 & 1.16 & 0.80 & 1.69 & $\underline{1.64}$ & 1.13 & 2.36 \\
\hline \multicolumn{10}{|l|}{ Time } \\
\hline 2007 versus 2006 & $\underline{1.56}$ & 1.18 & 2.06 & $\underline{1.71}$ & 1.27 & 2.29 & 1.19 & 0.88 & 1.61 \\
\hline $\mathrm{N}=$ & & 996 & & & 958 & & & 983 & \\
\hline Degrees of Freedom $=$ & & 21 & & & 21 & & & 21 & \\
\hline Percentage Yes $($ weighted $)=$ & & 51.2 & & & 33.5 & & & 52.3 & \\
\hline Wald $\mathrm{F}=$ & & $\underline{3.85}$ & & & 3.34 & & & $\underline{6.49}$ & \\
\hline
\end{tabular}

SOURCE: Tarrant County Senior Center Survey. NOTE: ${ }^{a}$ White is the contrast category. ${ }^{\mathrm{b}}$ Under age 85 is the contrast category. ${ }^{\mathrm{c}}$ Married is the contrast category. LEGEND: Odds ratios in bold are significant at the .05 level, 2-tailed test. Underlined odds ratios in bold are significant at the .01 level, 2 -tailed test.

result in no difference overall in overall activity, suggesting that those living alone are more likely to undertake physical activity outside the SCs.

Among enabling factors, only attendance at the center for at least a year showed any effect. Interestingly, those attending at least a year were about three-fifths as likely as those attending less than a year to report increased physical activity.

The strongest predictor of reported overall physical activity was physician recommendations. Those reporting being told by physicians to increase their exercise were three times as likely as others to report having done so. Those told by doctors to control or lose weight were also much-more likely to report increased physical activ- ity in the prior year. Controlling for participation in SC physical activities (Equation (2)), the effect of physician instructions to exercise was found to be weaker but still strongly positive; but the effect of physician instructions to lose weight was no longer significant. Thus, it appears that physician instructions to lose weight resulted in increased physical activity in large part by way of participation in SC physical activities. By contrast, instructions to exercise are associated with greater increased physical activity whether or not respondents did so via participation in SC physical-activities. Thus, offering of physical activities at SCs and physician recommendations to increase exercise are both important to increasing physical activity among seniors. 
Table 3. Logistic regression analysis: increased physical activity.

\begin{tabular}{|c|c|c|c|c|c|c|}
\hline & \multicolumn{3}{|c|}{ Equation (1) } & \multicolumn{3}{|c|}{ Equation (2) } \\
\hline & Odds Ratio & $\begin{array}{l}\text { Lower } \\
\text { Bound }\end{array}$ & $\begin{array}{l}\text { Upper } \\
\text { Bound }\end{array}$ & Odds Ratio & $\begin{array}{l}\text { Lower } \\
\text { Bound }\end{array}$ & $\begin{array}{l}\text { Upper } \\
\text { Bound }\end{array}$ \\
\hline \multicolumn{7}{|l|}{ Independent Variables: } \\
\hline \multicolumn{7}{|l|}{ Predisposing } \\
\hline African American ${ }^{\mathrm{a}}$ & 1.07 & 0.74 & 1.54 & 1.05 & 0.68 & 1.62 \\
\hline Hispanic $^{\mathrm{a}}$ & 0.59 & 0.39 & 0.91 & 1.03 & 0.59 & 1.81 \\
\hline Other Nonwhite $^{\mathrm{a}}$ & 1.54 & 0.69 & 3.45 & 1.19 & 0.43 & 3.29 \\
\hline Age & 0.98 & 0.96 & 1.01 & 0.98 & 0.95 & 1.01 \\
\hline Aged 85 or Over $^{\mathrm{b}}$ & 1.20 & 0.72 & 2.00 & 1.21 & 0.67 & 2.18 \\
\hline Male & 1.31 & 0.95 & 1.80 & $\underline{1.86}$ & 1.25 & 2.77 \\
\hline Single $^{c}$ & 0.52 & 0.29 & 0.92 & 0.51 & 0.25 & 1.02 \\
\hline Widowed $^{c}$ & 0.82 & 0.54 & 1.24 & 0.85 & 0.51 & 1.42 \\
\hline Divorced $^{\mathrm{c}}$ & 1.07 & 0.63 & 1.82 & 1.31 & 0.72 & 2.30 \\
\hline Live Alone & 1.38 & 0.97 & 1.95 & 1.56 & 1.04 & 2.36 \\
\hline Agree Interactions Important & 1.11 & 0.65 & 1.90 & 1.11 & 0.57 & 2.15 \\
\hline Strongly Agree Interactions Important & 1.32 & 0.98 & 1.80 & 1.24 & 0.86 & 1.78 \\
\hline \multicolumn{7}{|l|}{ Enabling } \\
\hline Needs Transit Help to Attend SC & 0.98 & 0.63 & 1.53 & 0.97 & 0.58 & 1.64 \\
\hline Attended Center for at Least 1 Year & 0.57 & 0.39 & 0.84 & 0.59 & 0.38 & 0.91 \\
\hline Attended Center for at Least 5 Years & 0.85 & 0.61 & 1.17 & 0.92 & 0.62 & 1.36 \\
\hline Attended Center at Least $3 x$ per Week & 1.13 & 0.82 & 1.55 & 0.90 & 0.61 & 1.33 \\
\hline Ctr. Only Interaction Source-Disagree & 1.06 & 0.65 & 1.70 & 1.04 & 0.58 & 1.88 \\
\hline Ctr. Only Interaction Source-Agree & 0.94 & 0.56 & 1.58 & 1.06 & 0.55 & 2.03 \\
\hline \multicolumn{7}{|l|}{ Need } \\
\hline Physician Said to Increase Exercise & $\underline{3.13}$ & 2.24 & 4.36 & $\underline{2.78}$ & 1.87 & 4.14 \\
\hline Physician Said to Control/Lose Weight & 1.43 & 1.02 & 2.01 & 1.13 & 0.75 & 1.70 \\
\hline \multicolumn{7}{|l|}{ Endogenous } \\
\hline Participates in Physical Fitness at Ctr. & & & & $\underline{1.70}$ & 1.13 & 2,54 \\
\hline Participates in Dance/Aerobics at Ctr. & & & & 1.93 & 1.28 & 2.92 \\
\hline Participates in Chair Exercises at Center & & & & 1.67 & 1.10 & 2.54 \\
\hline \multicolumn{7}{|l|}{ Time } \\
\hline 2007 versus 2006 & 1.31 & 0.99 & 1.72 & 1.21 & 0.88 & 1.69 \\
\hline $\mathrm{N}=$ & & 1167 & & & 898 & \\
\hline Degrees of Freedom $=$ & & 21 & & & 24 & \\
\hline Percentage Yes $=$ & & 57.1 & & & 56.7 & \\
\hline Model Chi-Square $=$ & & $\underline{7.13}$ & & & $\underline{5.76}$ & \\
\hline
\end{tabular}

SOURCE: Tarrant County Senior Center Survey. NOTE: ${ }^{\mathrm{a}}$ White is the contrast category. ${ }^{\mathrm{b}}$ Under age 85 is the contrast category. ${ }^{\mathrm{c}}$ Married is the contrast category. LEGEND: Odds ratios in bold are significant at the .05 level, 2-tailed test. Underlined odds ratios in bold are significant at the .01 level, 2 -tailed test.

\section{CONCLUSIONS}

Many predisposing factors predicted participation in SC physical activities but not in overall increased physical activity. African Americans were more likely than whites to report SC physical activity and SC chair exercises. Hispanics were less likely to report SC physical activity but more likely to participate in dance/aerobics. In general, findings for African Americans and some for Hispanics contradict a general view of lower physical activity by racial/ethnic minorities, suggesting greater utilization of SC programs to undertake activity, thereby overcoming the general tendency to less physical activeity.

Age factors were not shown to influence participation in other SC physical activities, other than a greater likelihood for chair exercise participation to increase with age, nor overall physical activity. These findings are compatible with those found for national samples [25], showing a complex pattern of activity by age groups and by age in general.

Contrary to a general view of higher male physical ac- 
tivity, sample males were less likely than females to report participation in SC physical-fitness and chair-exercise. Controlling for SC-specific activities, however, the coefficient for gender increased was not significant, suggesting that males might have been more likely than females to report increases in physical activity outside SCs. It could be that males tend to seek out other venues to increase physical activity; or it could be that males are more likely to report increased activity, even if they did not undertake it. Marital status was not shown to predict SC physical activity. However, those who lived alone were much less likely to participate in physical fitness programs and in chair exercises. No effects were found of individual enabling factors on increases in physical activity.

Longer tenure and more frequent participation at SCs both showed a higher likelihood of participation in SC physical activities; but controlling for such participation, those with longer tenure were less likely to report increased physical activity in the past year, perhaps reflecting ongoing SC physical activity. This underscores the importance of SCs in enabling as well as promoting physical activity among elders-in general, the SC appears important not only as a venue for physical activity but also as a social context for success in increasing such activity.

The findings for the need factors are most interesting. Physician recommendations to exercise did not predict SC physical activity but were among the strongest predictors of increases in physical activity. Physician instructions to lose weight were associated with greater participation in SC physical fitness programs as well as increases in physical activity, but the latter doesn't hold when participations in SC activities are controlled. Apparently, physician encouragement creates the perceived need and response to engage in physical activity, but in the case of weight-loss instructions are mediated by participation in $\mathrm{SC}$ activities.

\subsection{Limitations}

The analysis suffers from a number of common issues in research, especially program-assessment-based research: cross-sectional data, self-reporting by subjects, limited measures available to researchers from evaluation surveys, and questions of generalizability.

The cross-sectional nature of the data from the two yearly surveys is a major issue in light of the wish to consider causal effects. Nevertheless, reasonable assumptions allow feasible conclusions on causality. Although it is possible that subjects engaging in, or increasing, their physical activity requested physician comments, it is far more reasonable to assume rather that physician recommendations led to increased physical activity. Likewise, although possible that those who had already increased their physical activity during a year subsequently sought $\mathrm{SC}$ exercise activities, it is far more reasonable to assume either that those increasing their activity were already participated in the SC programs or especially that the SC programs were among the modalities chosen in order to increase physical activity.

Although the factors available do not lend themselves to many health education models, they do allow use of a sociological model that emphasizes contextual as well as individual factors. In this respect, the Andersen model, especially with its emphasis on predisposing and enabling factors, fits well with available data. An unfortunate exception is the lack of consistent measures of transportation as an enabling factor. Although physical activity is a universal need, unlike the services for which the Andersen model was developed, its consideration of perceptions of need also lends itself to the specific measures available in the assessment surveys.

Self-reporting is an issue not just in evaluation research but in much research involving physical activity. This cannot be avoided without much more costly, intrusive approaches which were not undertaken for the assessments of SC programs in this case.

Generalizability issues arise both in sampling of subjects from among SC participants and the limitation of the study to a single county's system of SCs. Data collection was based on attempts to sample all participants on a given day at each $\mathrm{SC}$, but such a daily census obviously cannot assure representation of all days in the year. Likewise, such a daily census does not ensure representtativeness across centers, although we attempted to correct somewhat for this by weighting by yearly data on center size, based on yearly congregate meal participation. The overall samples deriving from a single large metropolitan county cannot be avoided, given the nature of research based on assessment surveys.

\subsection{Implications for Practice}

Physician recommendations are often successful in increasing physical activity which has been documented in the literature, as has been the success of SC programs in so doing. What is interesting here is the existence of self-reported data on both and the apparent linkages among physician recommendations, participation in SC programs, and overall increases in physical activity. This allows suggestions regarding the interplay of physician and senior center in promoting physical activity in the aged.

Physician recommendations and SC factors interact with each other in predicting increased physical activity among SC participants, implying that both SCs and physicians are important to promote physical activity in elders. Physicians should urge, particularly prescribe, physical activity $[1,73]$; but better is SC-physician collabora- 
tion to encourage physical activity (see [57]). Such collaboration is not simple, given the disparate nature of SC attendance and choice of physicians. Nevertheless, development of collaboration among systems of SCs, medical societies, and local public health departments might allow generalizing community approaches to physical activity promotion. This would accord with the recommendations of Thurston and Green [56] and promotions of physical activity involving "understanding the social, cultural, physical, demographic and economic influences of individual action" rather than relying solely upon "personal action." The SC, with its aim of enhancing interpersonal socialization, could enhance such more holistic health promotion.

\section{ACKNOWLEDGEMENTS}

We thank Senior Citizen Services of Greater Tarrant County, Inc., for providing the data for this analysis.

\section{REFERENCES}

[1] Singh, M.A. (2002) Exercise comes of age: Rationale and recommendations for a geriatric exercise prescription. Journal of Gerontology: Medical Sciences, 57A, M262M282. http://dx.doi.org/10.1093/gerona/57.5.M262

[2] Sarkisian, C.A., Prohaska, T.R., Wong, M.D., Hirsch, S., Mangione, C.M. (2005) The relationship between expectations for aging and physical activity among older adults. Journal of General Internal Medicine, 20, 911-915. http://dx.doi.org/10.1111/j.1525-1497.2005.0204.x

[3] Robert Wood Johnson Foundation. (2005) National blueprint: Increasing physical activity among adults age 50 and over. Robert Wood Johnson Foundation, Princeton. http://www.activeforlife.info/about the program/files/blu eprint.pdf

[4] King, A.C. (2001) Interventions to promote physical activity by older adults. Journal of Gerontology Series A: Biological Sciences and Medical Sciences, 56, 36-46. http://dx.doi.org/10.1093/gerona/56.suppl_2.36

[5] Chastin, S.F.M., Ferrioli, E., Stephens, N.A., Fearon, K.C.H. and Greig, C. (2012) Relationship between sedentary behaviour, physical activity, muscle quality and body composition in healthy older adults. Age and Ageing, 41, 111-114. http://dx.doi.org/10.1093/ageing/afr075

[6] Harris, T.J., C.G. Owen, C.R. Victor,R. Adams, D.G. Cook (2009) What factors are associated with physical activity in older people, assessed objectively by accelerometry? British Journal of Sports Medicine, 43, 442-450. http://dx.doi.org/10.1136/bjsm.2008.048033

[7] Gulsvik, AK, DS Thelle, SO Samuelsen, M Myrstad, M Move, TB Wyller (2012) Ageing, physical activity and mortality-A 42-year follow-up study. International Journal of Epidemiology, 41, 521-530.

http://dx.doi.org/10.1093/ije/dyr205

[8] Gregg, E.W., J.A. Cauley, K. Stone, T.J. Thompson, D.C. Bauer, S.R. Cummings, K.E. Ensrud (2003) Relationship of changes in physical activity and mortality among older women. Journal of the American Medical Association, 289, 2379-2386. http://dx.doi.org/10.1001/jama.289.18.2379

[9] Duncan J.J.; N.F. Gordon; C.B. Scott (1991) Women walking for health and fitness. How much is enough? Journal of the American Medical Association, 266, 32953299. http://dx.doi.org/10.1001/jama.1991.03470230053030

[10] Dunn, A.L.; B.H. Marcus; J.B. Kampert; M.E. Garcia, H.W. Kohl, S.N. Blair (1999) Comparison of lifestyle and structured interventions to increase physical activity and cardiorespiratory fitness: A randomized trial. Journal of the American Medical Association, 281, 327-234. http://dx.doi.org/10.1001/jama.281.4.327

[11] Pate, R.R.; M. Pratt; S.N. Blair; W.L. Haskell; C.A. Macera; C. Bouchard; D. Buchner; W. Ettinger; G.W. Heath; A.C. King, et al. (1995) Physical activity and public health. A recommendation from the Centers for Disease Control and Prevention and the American College of Sports Medicine. Journal of the American Medical Association, 273, 402-407. http://dx.doi.org/10.1001/jama.1995.03520290054029

[12] Wen, C.P., Wai, J.P.M., Tsai, M.K., Yang, Y.C., Cheng, T.Y.D., Lee, M.-C., Chan, H.T., Tsao, C.K., Tsai, S.P. and Wu, X.F. (2011) Minimum amount of physical activity for reduced mortality and extended life expectancy: A prospective cohort study. The Lancet, 378, 1244-1253. http://dx.doi.org/10.1016/S0140-6736(11)60749-6

[13] Rejeski, W., A. King, J. Katula, S. Krithevsky, M. Miller, M. Walkup, N. Glynn, M. Pahor (2008) Physical activity in prefrail older adults: Confidence and satisfaction related to physical function. Journal of Gerontology: Psychological Sciences, 63B, P19-P26. http://dx.doi.org/10.1093/geronb/63.1.P19

[14] Petridou, E.T., E.G. Manti, A.G. Ntinapogias, E. Negri, K. Szczerbińska (2009) What works better for communitydwelling older people at risk to fall?: A meta-analysis of multifactorial versus physical exercise-alone interventions. Journal of Aging \& Health, 21, 713-729. http://dx.doi.org/10.1177/0898264309338298

[15] Friis, R., W.L. Nomura, C.X. Ma, J.H. Swan (2003) Socioepidemiologic and health-related correlates of walking for exercise among the elderly: Results from the longitudinal study of aging. Journal of Agingand Physical Activity, 11, 54-65.

[16] Gregg, E.W., Gerzoff, R.B., Caspersen, C.J., Williamson, D.F. and Narayan, K.M.V. (2003) Relationship of walking to mortality among US adults with diabetes. Archives of Internal Medicine, 163, 1440-1447. http://dx.doi.org/10.1001/archinte.163.12.1440

[17] Vogel, T., P.H. Brechat, P.M. Leprêtre, G. Kaltenbach, M. Berthel, J. Lonsdorfer (2009) Health benefits of physical activity in older patients: A review. International Journal of Clinical Practice, 63, 303-320. http://dx.doi.org/10.1111/j.1742-1241.2008.01957.x

[18] Depp, C.A., D.V. Jeste (2006) Definitions and predictors of successful aging: A comprehensive review of larger quantitative studies. American Journal of Geriatric Psy- 
chiatry, 14, 6-20.

http://dx.doi.org/10.1097/01.JGP.0000192501.03069.bc

[19] Centers for Disease Control and Prevention (2011) How much physical activity do older adults need? Physical Activity for Everyone: Older Adults.

http://www.cdc.gov/physicalactivity/everyone/guidelines/ olderadults.html

[20] Bijnen, F., Feskens, E., Caspersen, C., Mosterd, W. and Kromhout, D. (1998) Age, period, and cohort effects on physical activity among elderly men during 10 years of follow-up: The Zutphen elderly study. Journals of Gerontology Series A: Medical Sciences, 53, M235-M241.

[21] Evenson, K.R., S.Wilcox, M. Pettinger, R. Brunner, A.C. King, A. McTiernan (2002) Vigorous leisure activity through women's adult life: The women's health initiative observational cohort study. American Journal of Epidemiology, 156, 945-953.

http://dx.doi.org/10.1093/aje/kwf132

[22] Sun, F, IJ Norman, AE While (2013) Physical activity in older people: A systematic review. BMC Public Health, 13, 449-465. http://dx.doi.org/10.1186/1471-2458-13-449

[23] Centers for Disease Control and Prevention (1996) Physical Activity and Health: A Report of the Surgeon General. Centers for Disease Control and Prevention, National Center for Chronic Disease Prevention and Health Promotion, Atlanta.

[24] Frisard, M., J. Fabre, R. Russell, C. King, J. DeLany, R. Wood, E. Ravusin (2007) Physical activity level and physical functionality in nonagenarians compared to individuals aged 60-74 years. Journal of Gerontology, Medical Sciences, 62A, 783-788.

http://dx.doi.org/10.1093/gerona/62.7.783

[25] Swan, J.H., R. Friis, K. Turner (2008) Getting tougher for the fourth quarter: boomers and physical activity. Journal of Aging \& Physical Activity, 16, 261-279.

[26] Evenson, K., W. Rosamond, J.Cai, A.V. Diez-Roux, F. Brancati (2002) Influence of retirement on leisure-time physical activity. American Journal of Epidemiology, 155, 692-699. http://dx.doi.org/10.1093/aje/155.8.692

[27] Aday, R.H., G. Kehoe, L. Farney (2006) Impact of senior center friendships on aging women who live alone. Journal of Women \&Aging, 18, 57-73. http://dx.doi.org/10.1300/J074v18n01 05

[28] Kirk, A.B.; H.D. Alessi (2000) Senior service centers: A comparison of affiliated and nonaffiliated participants. Lifespan Journal, 2, 89-100.

[29] Eaton, J. and Salari, S. (2005) Environments for lifelong learning in senior centers. Educational Gerontology, 31, 461-480. http://dx.doi.org/10.1080/03601270590928189

[30] Towle, A., Godolphin, W., Manklow, J. and Wiesinger, H. (2003) Patient perceptions that limit a community-based intervention to promote participation. Patient Education and Counseling, 50, 231-233. http://dx.doi.org/10.1016/S0738-3991(03)00042-9

[31] Calsyn R.J. and Winter, J.P. (1999) Who attends senior centers? Journal of Social Service Research, 26, 53-69. http://dx.doi.org/10.1300/J079v26n02 03

[32] Miner, S., Logan, J.R. and Spitze, G. (1993) Predicting the frequency of senior center attendance. The Gerontologist, 33, 650-657.

http://dx.doi.org/10.1093/geront/33.5.650

[33] Aday, R.H (2003) The evolving role of senior centers in the 21 st century (testimony before senate special committee on aging).

http://aging.senate.gov/public/files/hr101ra.pdf

[34] Krout J.A., Cutler, S. and Coward, R. (1990) Correlates of senior center participation: A national analysis. The Gerontologist, 30, 72-79.

http://dx.doi.org/10.1093/geront/30.1.72

[35] Betza, B., Walwick, J., Shiu-Thornton, S., Schwartz, S., Taylor, M. and LoGerfo, J. (2004) Older adult perspectives on physical activity and exercise: Voices from multiple cultures. Preventing Chronic Disease, 1.

http://www.cdc.gov/pcd/issues/2004/oct/04_0028.htm

[36] Gelfand, D.E., Bechill, W. and Chester, R.L. (1991) Core programs and services at senior centers. Journal of Gerontological Social Work, 17, 145-161.

http://dx.doi.org/10.1300/J083v17n01 12

[37] Hernandez, R., Prohaska, T.R., Wang, P.-C. and Sarkisian, C.A. (2013) The longitudinal relationship between depression and walking behavior in older Latinos: The “¡Caminemos!” study. Journal of Aging \& Health, 25, 319. 341. http://dx.doi.org/10.1177/0898264312468488

[38] Rohr, M. and Lang, F. (2009) Aging well together-A mini-review. Gerontology, 55, 333-343. http://dx.doi.org/10.1159/000212161

[39] Cromwell, S.L. and Berg, J.A. (2006) Lifelong physical activity patterns of sedentary Mexican American women. Geriatric Nursing, 27, 209-213. http://dx.doi.org/10.1016/j.gerinurse.2006.06.008

[40] Dornelas, E.A., Stepnowski, R.R., Fischer, E.H. and Thompson, P.D. (2007) Urban ethnic minority women's attendance at health clinic vs. church based exercise programs. Journal of Cross-Cultural Gerontology, 22, 129136. http://dx.doi.org/10.1007/s10823-006-9023-1

[41] Evans, W.J. (1995) Effects of exercise on body composition and functional capacity of the elderly. The Journals of Gerontology Series A Biological and Medical Sciences, 50, 147-150.

[42] Jones, N.D., Della Corte, M.R., Nigg, C.R., Clark, P.G. and Burbank, P.M. (2001) Seniorcise: A print exercise intervention for older adults. Educational Gerontology, 27, 717-728. http://dx.doi.org/10.1080/036012701317117938

[43] Dunn, A.I., Andersen, R.E. and Jakicic, J.M. (1998) Lifestyle physical activity interventions: History, short- and long-term effects, and recommendations. American Journal of Preventive Medicine, 15, 398-412. http://dx.doi.org/10.1016/S0749-3797(98)00084-1

[44] Kolt, G.S., Schofield, G.M., Kerse, N., Garrett, N. and Oliver M. (2007) Effect of telephone counseling on physical activity for low-activity older people in primary care: A randomized, controlled trial. Journal of the American Geriatrics Society, 55, 986-992.

http://dx.doi.org/10.1111/j.1532-5415.2007.01203.x

[45] Stewart, A.L., Gillis, D., Grossman, M., Castrillo, M., McLellan, B., Sperber, N. and Pruitt, L. (2006) Diffusing 
a research-based physical activity promotion program for seniors into diverse communities: CHAMPS III. Preventing Chronic Disease, 3, A51-A66.

[46] Wallace, K.A. and Lahti, E. (2005) Motivation in later life: A psychosocial perspective. Topics in Geriatric Rehabilitation, 21, 95-106.

[47] Wilcox, S., Dowda, M., Griffin, S., Rheaume, C., Ory, M., Leviton, L., King, A., Dunn, A., Buchner, D., Bazzarre, T., Estabrooks, P., Campbell-Voytal, K., Bartlett-Prescott, J., Dowdy, D., Castro, C., Carpenter, R., Dzewaltowski, D. and Mockenhaupt, R. (2006) Results of the first year of active for life: Translation of 2 evidence-based physical activity programs for older adults into community settings. American Journal of Public Health, 96, 1201-1209. http://dx.doi.org/10.2105/AJPH.2005.074690

[48] Conn, V.S., Minor, M.A., Burks, K.J., Rantz, M.H. and Pomeroy, S.H. (2003) Integrative review of physical activity intervention research with aging adults. Journal of the American Geriatrics Society, 51, 1159-1168. http://dx.doi.org/10.1046/j.1532-5415.2003.51365.x

[49] Belza, B., Walwick, J., Shiu-Thornton, S., Schwartz, S., Taylor, M. and LoGerfo, J. (2004) Older adult perspectives on physical activity and exercise: Voices from multiple cultures. Preventing Chronic Disease, 1, A9. http://www.cdc.gov/pcd/issues/2004/oct/04_0028.htm

[50] Marcus, B.H., Forsyth, L.H., Stone, E.J., Dubbert, P.M., McKenzie, T.L., Dunn, A.L. and Blair, S.N. (2000) Physical activity behavior change: Issues in adoption and maintenance. Health Psychology, 19, 32-41. http://dx.doi.org/10.1037/0278-6133.19.Suppl1.32

[51] Batik, O., Phelan, E.A., Walwick, J.A., Wang, G. and LoGerfo, J.P. (2008) Translating a community-based motivational support program to increase physical activity among older adults with diabetes at community clinics: A pilot study of physical activity for a lifetime of success (PALS). Preventing Chronic Disease, 5, 1-7.

[52] Elley, C.R., Kerse, N., Arroll, B. and Robinson, E. (2003) Effectiveness of counselling patients on physical activity in general practice: Cluster randomised controlled trial. British Medical Journal, 326, 793.

[53] Fortier, M.S., Sweet, S.N., O’Sullivan, T.L. and Williams, G.C. (2007) A self-determination process model of physical activity adoption in the context of a randomized controlled trial. Psychology of Sport and Exercise, 8, 741-757. http://dx.doi.org/10.1016/j.psychsport.2006.10.006

[54] Katz, D.L., Shuval, K., Comerford, B.P., Faridi, Z. and Njike, V.Y. (2008) Impact of an educational intervention on internal medicine residents' physical activity counselling: The Pressure System Model. Journal of Evaluation in Clinical Practice, 14, 294-299. http://dx.doi.org/10.1111/j.1365-2753.2007.00853.x

[55] Sørensen, J.B., Kragstrup, J., Kjær, K. and Puggaard, L. (2007) Exercise on prescription: Trial protocol and evaluation of outcomes. BMC Health Services Research, 7, 3644. http://dx.doi.org/10.1186/1472-6963-7-36

[56] Duncan, G.E., Anton, S.D., Sydeman, S.J., Newton, R.L., Corsica, J.A., Durning, P.E., Ketterson, T.U., Martin, A.D., Limacher, M.C. and Perri, M.G. (2005) Prescribing exercise at varied levels of intensity and frequency: A ran- domized trial. JAMA Internal Medicine, 165, 2362-2369. http://dx.doi.org/10.1001/archinte.165.20.2362

[57] Thurston, M. and Green, K. (2004) Adherence to exercise in later life: How can exercise on prescription programmes be made more effective? Health Promotion International, 19, 379-387.

http://dx.doi.org/10.1093/heapro/dah311

[58] Leveille, S.G., Wagner, E.H., Davis, C., Grothaus, L., Wallace, J., LoGerto, M. and Kent, D. (1998) Preventing disability and managing chronic illness in frail older adults: A randomized trial of a community-based partnership with primary care. Journal of the American Geriatrics Society, 46, 1191-1198.

[59] Ahn, S., Smith, M.L. and Ory, M.G. (2012) Physicians' discussions about body weight, healthy diet, and physical activity with overweight or obese elderly patients. Journal of Aging \& Health, 24, 1179-1202.

http://dx.doi.org/10.1177/0898264312454573

[60] Lee, Y.S. (2005) Gender differences in physical activity and walking among older adults. Journal of Women \& Aging, 17, 55-70. http://dx.doi.org/10.1300/J074v17n01_05

[61] Crespo, C.J., Smit, E., Andersen, R.E., Carter-Porkras, O. and Ainsworth, B.E. (2000) Race/ethnicity, social class and their relation to physical inactivity during leisure time: Results from the third national health and nutrition examination survey, 1988-1994. American Journal of Preventative Medicine, 18, 46-53. http://dx.doi.org/10.1016/S0749-3797(99)00105-1

[62] Resnick, B., Vogel, A., Luisi, D. (2006) Motivating minority older adults to exercise. Cultural Diversity and Ethnic Minority Psychology by the American Psychological Association, 12, 17-29.

[63] Sotomayor, M., Dominguez, A. and Pawlik, F. (2007) Building community capacity for health promotion in a Hispanic community. Preventing Chronic Disease, 4, A16. http://www.cdc.gov/pcd/issues/2007/jan/06 0086.htm

[64] Andersen, R. (1968) A behavioral model of families' use of health services. Research Series No. 25. Center for Health Administration Studies, University of Chicago. Chicago.

[65] Andersen, R. (1995) Revisiting the behavioral model and access to medical care: Does it matter? Journal of Health and Social Behavior, 36, 1-10. http://dx.doi.org/10.2307/2137284

[66] Chen, Y.M., and Thompson, E.A. (2010) Understanding factors that influence success of home- and communitybased services in keeping older adults in community settings. Journal of Aging and Health, 22, 267-291. http://dx.doi.org/10.1177/0898264309356593

[67] Forbes, D.A., Morgan, D. and Janzen, B.L. (2006) Rural and urban Canadians with dementia: Use of health care services. Canadian Journal on Aging, 25, 321-330. http://dx.doi.org/10.1353/cja.2007.0003

[68] Lynch, M., Harrington, C. and Newcomer, R. (1999) Predictors of use of chronic care services by impaired members in the social health maintenance organization demonstration. Journal of Applied Gerontology, 18, 283-304. 
http://dx.doi.org/10.1177/073346489901800302

[69] Wolinsky, F.D., Coe, R.M., Miller, D.K., Penderghast, J.M., Creel, M.J. and Chavez, M.N. (1983) Health services utilization among the non-institutionalized elderly. Journal of Health and Social Behavior, 24, 325-337. http://dx.doi.org/10.2307/2136399

[70] Wister, A.V., Malloy-Weir, L.J., Rootman, I. and Desjardins, R. (2010) Lifelong educational practices and resources in enabling health literacy among older adults. Journal of Aging and Health, 22, 827-854. http://dx.doi.org/10.1177/0898264310373502

[71] Andersen, R.M., Yu, H., Wyn, R., Davidson, P., Brown, E.R. and Teleki, S. (2002) Access to medical care for moderate and low income families: How do communities make a difference? Medical Care Research and Review, 59, 384-411. http://dx.doi.org/10.1177/107755802237808

[72] Miller, E.A. and Weissert, W. G. (2000) Predicting elderly people's risk for nursing home placement, hospitalization, functional impairment, and mortality: A synthesis. Medical Care Research and Review, 57, 259-297. http://dx.doi.org/10.1177/107755870005700301

[73] Crespo, C.J. (2000) Encouraging physical activity in minorities: Eliminating disparities by 2010. Physician and Sportsmedicine, 28, 36-51.

http://dx.doi.org/10.3810/psm.2000.10.1230 